\title{
Races and Inoculum Density of Fusarium oxysporum f. sp. niveum in Commercial Watermelon Fields in Maryland and Delaware
}

X. G. Zhou, University of Maryland, Lower Eastern Shore Research and Education Center, 27664 Nanticoke Road, Salisbury, 21801; and K. L. Everts, University of Maryland, Lower Eastern Shore Research and Education Center, 27664 Nanticoke Road, Salisbury, 21801 and University of Delaware, 16684 County Seat Highway, Georgetown, 19947

\begin{abstract}
Zhou, X. G., and Everts, K. L. 2003. Races and inoculum density of Fusarium oxysporum f. sp. niveum in commercial watermelon fields in Maryland and Delaware. Plant Dis. 87:692-698.

A survey was conducted to determine races and inoculum density of Fusarium oxysporum f. sp. niveum, the causal agent of Fusarium wilt of watermelon in Maryland and Delaware. Virulence on six differential cultivars was tested for each of 63 isolates of $F$. oxysporum f. sp. niveum, obtained from 25 commercial watermelon fields. Thirteen isolates $(21 \%)$ were identified as race 0,36 isolates $(57 \%)$ as race 1 , and 14 isolates $(22 \%)$ as race 2 . Races 0 and 1 were present in 12 $(48 \%)$ and $10(40 \%)$ of the fields, respectively. The highly aggressive race 2 was identified from five fields in two counties in Maryland and from one field in Delaware, representing 24\% of the fields. Race 2 was copresent with one or two other races. Race 2 (19 isolates) predominated among the 25 isolates obtained from a research field in Maryland. Nineteen commercial fields had inoculum densities of $F$. oxysporum $\mathrm{f}$. sp. niveum ranging from 100 to $1,200 \mathrm{CFU} / \mathrm{g}$ of soil at harvest. Within this range of inoculum densities, $>20 \%$ incidence of wilt was observed when the susceptible watermelon cv. Sugar Baby was planted in samples of soil collected from these fields. The relationship $(P<0.0001)$ between inoculum density of $F$. oxysporum $\mathrm{f}$. sp. niveum $(X)$ and incidence of Fusarium wilt $(Y)$ on Sugar Baby was best described using the monomolecular equation, $Y=1-\exp ^{[-0.0013(X+166)]}$. The ratio of pathogenic to total population of $F$. $o x$ ysporum in the fields linearly increased with increasing inoculum density of $F$. oxysporum f. sp. niveum $\left(R^{2}=0.4 ; P<0.0009\right)$
\end{abstract}

Additional keyword: Citrullus lanatus

Fusarium wilt of watermelon (Citrullus lanatus (Thunb.) Matsum. \& Nakai), caused by Fusarium oxysporum f. sp. niveum (E.F. Sm.) W.C. Snyder \& H.N. Hans., has become a major yield-limiting disease in Maryland and Delaware where the acreage of watermelon is the second highest for fresh-market vegetables grown in the region. Currently, host resistance is the most common method used to control Fusarium wilt in comparison with other management approaches such as fumigation $(8,10)$, crop rotation $(11,20)$, soil solarization $(8,23)$, and biocontrol (21). The effectiveness of host resistance is largely dependent on the prevalence of specific races of the pathogen and level of inoculum in the soil $(3,20,24)$. Knowledge of the races and inoculum densities of $F$. $o x$ ysporum $\mathrm{f}$. sp. niveum in commercial fields could facilitate development of more efficient, regional management strategies for control of Fusarium wilt of watermelon.

Corresponding author: K. L. Everts

E-mail: ke35@umail.umd.edu

Accepted for publication 23 January 2003.

Publication no. D-2003-0407-02R

(C) 2003 The American Phytopathological Society
Three races (races 0, 1, and 2) of Fusarium oxysporum $\mathrm{f}$. $\mathrm{sp}$. niveum have been described based on the disease reactions of differential watermelon genotypes to inoculation with isolates of the fungus $(5,6,19,22$, 28,29 ). Race 0 is the least aggressive race and only causes wilt on cultivars with no wilt-resistance genes, such as cvs. Sugar Baby and Black Diamond. Race 1, which is intermediate in aggressiveness, causes slight to moderate wilt on most cultivars that are classified as resistant to Fusarium wilt. Race 2 is highly aggressive and can overcome the wilt-resistance in all commercial watermelon cultivars currently available.

The geographical distribution differs for each of the three races of $F$. oxysporum $\mathrm{f}$. sp. niveum $(3,22)$. Race 0 has only been reported in Florida (7), Oklahoma (22), Texas (22), Spain (8), and Italy (5). Race 1 is the most frequently isolated race in areas of watermelon production surveyed within the United States (22). Two isolates of $F$. oxysporum f. sp. niveum collected from Maryland were identified as race 1 (15). In contrast, the geographical distribution of race 2 appears to be much more limited $(3,22)$. In the United States, race 2 was initially found in Texas $(18,19)$, Oklahoma (4), and Florida $(15,22)$. More recently, race 2 was found in Maryland and Delaware (33). Race 2 was first observed in
Israel in $1973(28,29)$, and has since been reported in several Mediterranean countries including Greece (28), Turkey (28), Spain (8), and Cyprus (13).

Little is known about the range and distribution of inoculum densities of $F$. $o x$ ysporum f. sp. niveum in infested commercial fields used for watermelon production in Maryland and Delaware, as well as other areas of the world. In Israel, Netzer (28) determined that the population of $F$. oxysporum f. sp. niveum within a single heavily infested watermelon field ranged from 400 to $1,400 \mathrm{CFU} / \mathrm{g}$ of soil. Within this range of inoculum densities, $>95 \%$ of the seedlings of the watermelon cv. Sugar Baby wilted in a greenhouse bioassay. In Florida, Hopkins and Elmstrom (11) reported that populations of $F$. oxysporum averaged around 1,500 CFU/g of soil in most research plots that had been cropped to watermelon.

The objectives of this study were to (i) conduct a survey of the frequency and distribution of races and inoculum density of $F$. oxysporum f. sp. niveum in commercial watermelon fields in Maryland and Delaware; and (ii) assess the potential for development of Fusarium wilt in these fields based on soil assays using a susceptible cultivar of watermelon.

\section{MATERIALS AND METHODS}

Sampling of infected plants and isolation of $\boldsymbol{F}$. oxysporum. Roots and crowns of 395 watermelon plants were collected during harvest (July through September) from 25 commercial watermelon fields in 2000 and from one research field in 1999 and 2000. The commercial fields were located in Wicomico, Dorchester, and Caroline counties in Maryland, and in Sussex County in Delaware. These counties comprised the largest commercial watermelon acreage in each state in 2000, accounting for more than $65 \%$ of the total watermelon acreage. The fields surveyed represented approximately 16 and $13 \%$ of the acreage of watermelon crops planted in Maryland and Delaware, respectively, in 2000. The research field was located at the University of Maryland Lower Eastern Shore Research and Education Center in Wicomico County and had been cropped to watermelon cultivars ranging from susceptible to resistant to Fusarium wilt for 22 of the previous 25 years. 
Twelve to twenty plants showing symptoms of Fusarium wilt (wilting and vascular discoloration) were randomly sampled from each field. Each plant was uprooted, the vines removed approximately $10 \mathrm{~cm}$ above the crown, and the crown and root packaged in a plastic bag. Each plant was washed under running tap water for approximately $1 \mathrm{~min}$ and cut into three parts, a stem, crown, and root section. Each plant section (20 to $30 \mathrm{~mm}$ long) was surfacedisinfected in a $5.5 \%$ solution of $\mathrm{NaOCl}$ for $2 \mathrm{~min}$, rinsed three times in sterilized water, and air-dried on a sterile paper towel. Each disinfected section was cut into two pieces (4 to $25 \mathrm{~mm}^{2}$ ). All six pieces from each plant sample were plated on one $10-\mathrm{cm}$-diameter petri plate filled with Komada's Fusarium-selective medium (14). Fusarium-like colonies were selected 7 to 10 days after incubation at room temperature in the dark and transferred individually to potato dextrose agar (PDA) plates. Identification of $F$. $o x$ ysporum was based on the criteria provided by Nelson et al. (26). Single microconidia cultures of all isolates of $F$. oxysporum were made (26) and maintained at $4^{\circ} \mathrm{C}$ in test tubes filled with sterilized sand.

Pathogenicity test and race determination. The method of inoculation used for isolates of $F$. oxysporum f. sp. niveum was similar to that developed by Larkin et al. (15), and the pipette method developed by Latin and Snell (17). Initial pathogenicity tests were conducted in a greenhouse by inoculating isolates of $F$. oxysporum onto plants of the susceptible watermelon $\mathrm{cv}$. Sugar Baby to separate pathogenic from nonpathogenic isolates. The race of each pathogenic isolate was then determined using six differential watermelon cultivars: Sugar Baby, Crimson Sweet, Charleston Gray, Allsweet, Dixielee, and Calhoun Gray, which range from susceptible to highly resistant to infection by race 1 of $F$. oxysporum f. sp. niveum $(2,7,15,24)$. A monoconidial culture of each isolate was grown in a liquid mineral salts medium (28) on a rotary shaker (128 rpm) under a 12-h photoperiod at room temperature for 5 to 6 days. A spore suspension (primarily microconidia) was obtained for each culture by filtering the culture through four layers of cheesecloth. The density of the spore suspension of each isolate was determined with a hemacytometer and adjusted to $10^{6}$ conidia/ml. A reference isolate of $F$. oxysporum f. sp. niveum race 0 (TX-471) was obtained from B. Bruton of the USDA Southern Agriculture Research Laboratory in Lane, OK, and a reference isolate of each of race 1 (ATCC44293) $(28,30)$ and race 2 (TX-X1D, ATCC62939) (19) of $F$. oxysporum f. sp. niveum was purchased from the American Type Culture Collection (ATCC) in Manassas, VA. These isolates were included in the evaluations for pathogenicity and race determination. Dilute sterilized mineral salts medium
(1:2 mineral salts/water) and sterilized water served as noninoculated control treatments.

Seeds were planted in 8-cm-diameter pots containing $350 \mathrm{~cm}^{3}$ of pasteurized vermiculite-peat moss $(2: 3 \mathrm{vol} / \mathrm{vol})$ potting medium (Scotts-Sierra Horticultural Products Co., Maryville, OH) infested with approximately $10^{5}$ microconidia per $\mathrm{g}$ of potting medium. Five seedlings in each of three replicate pots were inoculated for initial pathogenicity tests. Seven to ten seedlings of each of the six differential watermelon cultivars in each of three replicate pots were used for subsequent race determinations. All plants were maintained in a greenhouse at 20 to $28^{\circ} \mathrm{C}$ using a Horticultural Environment Controller (Model Step 50A, Vadsworth Control System, Inc., Arvada, CO). Seedlings were watered and fertilized as needed to maintain normal growth. The number of seedlings showing symptoms of Fusarium wilt (yellowing, stunting, or wilting) in each pot was counted 3 to 4 weeks after inoculation. All fungal isolates were tested twice on all six differential watermelon cultivars. An additional one to three tests was conducted for those isolate-cultivar combinations for which the disease reactions were unclear. Isolates were assigned the appropriate race based on their virulence on the differential watermelon cultivars $(12,15,22)$. Isolates were considered race 0 if wilt incidence of $>15 \%$ occurred only in Sugar Baby, and if they caused a low mean wilt incidence across all six cultivars $(<33 \%)$. Isolates were considered race 1 if wilt incidence of $\leq 50 \%$ occurred in Calhoun Gray, Dixielee, and Allsweet, and if they caused an intermediate mean wilt incidence across all six cultivars (33 to 66\%). Isolates were considered race 2 if they caused a high wilt incidence $(>50 \%)$ in all six cultivars and a high mean wilt incidence ( $>66 \%)$.

Population survey and disease potential of surveyed fields. To quantify the inoculum density of $F$. oxysporum f. sp. niveum in commercial watermelon fields in which the crop showed symptoms of Fusarium wilt, 12 to 20 soil samples were collected from each field at the same time symptomatic watermelon plants were sampled. For each soil sample, approximately $500 \mathrm{~g}$ of soil was collected from the top 10 to $20 \mathrm{~cm}$ of soil and within $25 \mathrm{~cm}$ of a symptomatic plant. All soil samples were stored at $4^{\circ} \mathrm{C}$ until used.

Soil samples from the same field were combined into one sample and mixed thoroughly. The population of $F$. oxysporum in each field soil sample was determined by plating aliquots of a dilution series of the soil. A 10-g (dry weight equivalent) subsample of the soil was added to $90 \mathrm{ml}$ of $0.1 \%$ autoclaved water agar in a 500-ml flask. The resulting soil suspension was mixed for 5 min using a magnetic stirrer. One milliliter of this suspension $\left(10^{-1}\right.$ soil dilution) was plated onto each of two petri plates of Komada's medium (14). A second 1 -ml aliquot of the suspension was transferred to a test tube containing $9 \mathrm{ml}$ of $0.1 \%$ autoclaved water agar $\left(10^{-2}\right.$ dilution). One milliliter of this suspension was plated onto each of two petri plates of Komada's medium. Three replicates of soil dilutions were prepared for each field sampled. All plates were incubated at room temperature in the dark for 7 to 10 days, and the total number of colonies of $F$. oxysporum was counted.

The ratio of pathogenic to nonpathogenic colonies of $F$. oxysporum for each field sampled was determined by virulence tests of random, representative colonies. The number of colonies selected for pathogenicity tests from each field was determined as follows: (i) all colonies were tested if the total number of colonies of $F$. oxysporum on all the plates for a field was $\leq 30$; and (ii) 30 colonies were selected randomly if the total number of colonies was $>30$. The number of colonies selected represented from 10 to $100 \%$ of the total population of $F$. oxysporum in the sample of soil from each field. Colonies typical of F. oxysporum were transferred individually into $10-\mathrm{ml}$ vials containing $5 \mathrm{ml}$ of a liquid mineral salts medium (28). Fungal cultures were incubated and inoculum prepared as described previously. A $1.5-\mathrm{ml}$ sample of each fungal culture $\left(10^{4}\right.$ to $10^{5}$ conidia/ml $)$ was pipetted into an $80-\mathrm{cm}^{3}$ cell in a plastic tray (128 cells per tray) containing the potting medium described above. Three seeds of the watermelon cv. Sugar Baby were placed in each cell before inoculation. Plants were maintained in the greenhouse as described above and observed for symptoms of Fusarium wilt. A fungal isolate was regarded as pathogenic if at least one seedling per cell developed symptoms typical of Fusarium wilt (wilting, stunting, or yellowing) 3 to 4 weeks after inoculation.

The potential for development of Fusarium wilt in each of 25 commercial watermelon fields was evaluated by planting seeds of the watermelon cv. Sugar Baby in $216-\mathrm{cm}^{3}$ pots each filled with $173 \mathrm{~cm}^{3}$ of soil collected from the field. Three replicate pots each with 10 seedlings were used per field surveyed. A Norfolk "A" loamy sand soil that had been cropped to Kentucky Bluegrass (Poa pratensis L.), and that had been shown to be free of $F$. oxysporum f. sp. niveum (by serial dilution to Komada's medium and by the greenhouse bioassay described above) served as the noninfested control soil. All plants were maintained in the greenhouse as described previously. The incidence of wilted seedlings was assessed weekly for 6 weeks after seeding. Fungal growth on symptomatic seedlings or cultures isolated from infected seedlings onto Komada's medium was examined microscopically to confirm that it was $F$. oxysporum. The experiment was repeated. 
Data analysis. Differences in the incidence of Fusarium wilt on the differential watermelon cultivars for isolates of $F$. oxysporum f. sp. niveum were determined by analysis of variance (ANOVA), and means were compared using Fisher's protected least significant difference (LSD) at $P \leq 0.05$. No significant interactions of experiment by isolate or cultivar $(P \geq 0.07)$ for the two repeated experiments occurred. Therefore, they were combined for analysis, and results are presented for the combined analysis. Data on the proportion of seedlings showing symptoms of Fusarium wilt were arcsine-square root transformed to normalize data (31), but backtransformed after analysis for presentation of results. Statistical analyses were performed using the General Linear Model
(GLM) procedure of the Statistical Analysis System (SAS, Version 8.0, SAS Institute, Cary, NC). Data on the ratios of pathogenic to nonpathogenic population of $F$. oxysporum f. sp. niveum were transformed into the ratios of pathogenic to total population, and regressed on inoculum densities of $F$. oxysporum $\mathrm{f}$. sp. niveum for 25 commercial watermelon fields using the linear regression with PROC REG of SAS (27). Nonlinear regression procedures were performed to characterize the relationship between inoculum density of $F$. oxysporum f. sp. niveum in commercial fields and incidence of Fusarium wilt on Sugar Baby. Parameters of the nonlinear equation were estimated using the derivative-free option DUD of NLIN of SAS (27). Overparameterization and fit of the equation were evaluated by: (i) inspection of observed values and predicted values for incidence of Fusarium wilt plotted against population density of $F$. oxysporum $\mathrm{f}$. sp. niveum; (ii) standardized residual errors plotted against predicted values; and (iii) standard errors of parameter estimates (27). The inoculum densities for Fields 3 and 18 were identified as anomalous observations from the residual plots against predicted values by the regression analysis and were not used to estimate parameters of the equation.

\section{RESULTS}

Pathogenicity test and race determination. Of 153 isolates of $F$. oxysporum obtained from this survey, 88 isolates were pathogenic on the susceptible watermelon

Table 1. Incidence (\%) of plants with symptoms of Fusarium wilt for six differential watermelon cultivars inoculated with isolates of Fusarium oxysporum f. sp. niveum collected from 25 commercial watermelon fields in Maryland and Delaware in 2000

\begin{tabular}{|c|c|c|c|c|c|c|c|c|}
\hline \multicolumn{2}{|c|}{ F. oxysporum f. sp. niveum } & \multicolumn{7}{|c|}{ Differential watermelon cultivar } \\
\hline Isolate $^{w}$ & $\operatorname{Race}^{x}$ & Calhoun Gray & Dixielee & Allsweet & Charleston Gray & Crimson Sweet & Sugar Baby & Mean \\
\hline F-053-1 & 0 & $0^{y}$ & 0 & 0 & 0 & 0 & 17 & 3 \\
\hline F-095-1 & 0 & 0 & 0 & 0 & 0 & 0 & 28 & 5 \\
\hline F-060-1 & 0 & 0 & 0 & 0 & 0 & 0 & 39 & 7 \\
\hline F-005-1 & 0 & 0 & 0 & 0 & 8 & 0 & 72 & 13 \\
\hline F-117-1 & 0 & 0 & 0 & 7 & 0 & 14 & 61 & 14 \\
\hline TX-471 & 0 & 0 & 0 & 0 & 7 & 5 & 78 & 15 \\
\hline F-081-1 & 0 & 0 & 0 & 0 & 0 & 0 & 100 & 17 \\
\hline F-029-2 & 0 & 0 & 0 & 0 & 8 & 9 & 94 & 19 \\
\hline ATCC-44293 & 1 & 13 & 14 & 29 & 31 & 48 & 76 & 35 \\
\hline $\mathrm{F}-021-2$ & 1 & 10 & 42 & 27 & 20 & 38 & 100 & 39 \\
\hline F-022-1 & 1 & 13 & 31 & 33 & 33 & 38 & 100 & 41 \\
\hline F-015-1 & 1 & 7 & 39 & 13 & 33 & 57 & 94 & 41 \\
\hline F-021-3 & 1 & 7 & 20 & 33 & 18 & 76 & 100 & 42 \\
\hline F-029-1 & 1 & 13 & 12 & 20 & 48 & 95 & 100 & 48 \\
\hline F-086-1 & 1 & 13 & 30 & 40 & 33 & 76 & 100 & 49 \\
\hline F-061-1 & 1 & 7 & 12 & 33 & 67 & 81 & 94 & 49 \\
\hline F-083-2 & 1 & 17 & 43 & 40 & 50 & 48 & 100 & 50 \\
\hline F-067-2 & 1 & 7 & 36 & 47 & 44 & 72 & 100 & 51 \\
\hline F-067-1 & 1 & 13 & 39 & 20 & 69 & 76 & 94 & 52 \\
\hline F-100-1 & 1 & 7 & 20 & 20 & 68 & 95 & 100 & 52 \\
\hline F-030-1 & 1 & 13 & 14 & 27 & 67 & 95 & 100 & 53 \\
\hline F-028-1 & 1 & 7 & 11 & 33 & 70 & 95 & 100 & 53 \\
\hline F-049-2 & 1 & 30 & 34 & 20 & 72 & 95 & 100 & 59 \\
\hline F-018-1 & 1 & 20 & 36 & 27 & 69 & 100 & 100 & 59 \\
\hline F-099-2 & 1 & 27 & 38 & 40 & 67 & 95 & 100 & 61 \\
\hline F-107-1 & 1 & 23 & 40 & 33 & 72 & 95 & 100 & 61 \\
\hline F-088-1 & 1 & 23 & 31 & 47 & 78 & 91 & 100 & 62 \\
\hline F-084-1 & 2 & 77 & 71 & 60 & 63 & 81 & 100 & 75 \\
\hline F-099-1 & 2 & 73 & 70 & 53 & 66 & 95 & 100 & 76 \\
\hline TX-X1D & 2 & 63 & 59 & 67 & 86 & 81 & 100 & 76 \\
\hline F-085-1 & 2 & 70 & 72 & 53 & 75 & 95 & 100 & 78 \\
\hline F-063-2 & 2 & 67 & 58 & 73 & 94 & 95 & 100 & 81 \\
\hline F-087-1 & 2 & 77 & 93 & 73 & 75 & 76 & 100 & 82 \\
\hline F-085-2 & 2 & 73 & 69 & 80 & 100 & 95 & 100 & 86 \\
\hline F-032-1 & 2 & 80 & 77 & 80 & 92 & 90 & 100 & 87 \\
\hline $\mathrm{LSD}_{0.05} \mathrm{z}$ & & 16 & 25 & 25 & 35 & 21 & 15 & \\
\hline Mean & & 24 & 32 & 32 & 48 & 63 & 90 & \\
\hline
\end{tabular}

${ }^{\text {w }}$ Thirty-two isolates of Fusarium oxysporum f. sp. niveum, selected from 63 isolates recovered from infected watermelon plants in commercial fields, represent the range of disease reactions of different races of the pathogen on the differential watermelon cultivars. TX-471 was the reference isolate for race 0 (obtained from B. D. Bruton of the USDA in Lane, OK), and ATCC-44293 and TX-X1D (ATCC-62939) were the reference isolates for races 1 and 2, respectively (obtained from the American Type Culture Collection (ATCC) in Manassas, VA).

${ }^{x}$ Race designation was determined by inoculation of six differential watermelon cultivars $(12,15,22)$. Isolates were designated as: (i) race 0 if wilt incidence $(>15 \%)$ occurred only on Sugar Baby; (ii) race 1 if wilt incidence was $\leq 50 \%$ on Calhoun Gray, Dixielee, and Allsweet, with a mean wilt incidence over all six cultivars of 33 to $66 \%$; and (iii) race 2 if wilt incidence was $>50 \%$ on all six cultivars, with a mean wilt incidence of $>66 \%$.

y Percent wilt was calculated as the mean percentage of watermelon seedlings showing symptoms of Fusarium wilt for three replicate pots each containing 7 to 10 plants. Plants were rated for Fusarium wilt 3 to 4 weeks after inoculation ( $\sim 10^{5}$ conidia of $F$. oxysporum f. sp. niveum per $\mathrm{g}$ of potting medium). Plants were maintained in a greenhouse at 20 to $28^{\circ} \mathrm{C}$. Noninoculated control plants remained healthy.

${ }^{\mathrm{z}} \mathrm{LSD}_{0.05}$ is Fisher's protected least significant difference at $P \leq 0.05$ (31). Results of two experiments were combined for analysis since interactions of experiment by isolate or cultivar were insignificant $(P \geq 0.07)$. Wilt values were arcsine-square root transformed to normalize data and then backtransformed after analysis for presentation. 
cv. Sugar Baby. Thus, these isolates were identified as $F$. oxysporum f. sp. niveum and used for race determinations. Of the 88 isolates of $F$. oxysporum f. sp. niveum, 63 isolates were recovered from infected watermelon plants in 19 of the 25 commercial watermelon fields in 2000, 10 isolates from soil samples collected in 1999, and 15 isolates from infected watermelon plants at the University of Maryland research field in 2000. No race determinations were made for isolates obtained from soil samples from the commercial fields. Results for 32 of the 63 isolates from the commercial fields and 13 of the 25 isolates from the research field were presented to represent the range of disease reactions of different races on the differential cultivars.

Inoculation with race 0 isolates of $F$. oxysporum f. sp. niveum from commercial fields and the research field induced a high incidence of wilt on Sugar Baby, but no disease or low incidence (5 to $14 \%$ ) of wilt on all five cultivars with resistance genes to Fusarium wilt (Tables 1 and 2). Inoculation with race 1 isolates resulted in low to moderate incidences of Fusarium wilt on cvs. Calhoun Gray (7 to 33\%), Dixielee (11 to $43 \%$ ), and Allsweet (13 to $47 \%$ ), with mean incidence of wilted plants of 35 to $62 \%$ across all six differential cultivars. Race 2 isolates were highly aggressive on all six cultivars. They caused high incidences of wilt (53 to100\%) on cvs. Cal- houn Gray, Dixielee, and Allsweet, which are considered highly resistant to race 1 . Inoculation with these isolates resulted in a mean incidence of wilt ranging from 75 to 92\% across all six cultivars. Differentiation of the three races was more distinct on the resistant cultivars when calculating the mean incidence of wilt of all isolates of each race (Table 3 ). The reference isolates of races 0,1 , and 2 caused incidences of Fusarium wilt within the expected range for the respective races on the differential watermelon cultivars.

Frequency and distribution of races of F. oxysporum f. sp. niveum. Of the 63 isolates of $F$. oxysporum $\mathrm{f}$. sp. niveum obtained from commercial fields, 13 isolates $(21 \%)$ were identified as race 0,36 isolates $(57 \%)$ were race 1 , and 14 isolates $(22 \%)$ were race 2 (Tables 3 and 4). In the 25 commercial fields surveyed, isolates of race 0 and race 1 were recovered from 12 $(48 \%)$ and $10(40 \%)$ of the fields in the four counties across both states, respectively (Table 4). Isolates of race 2 were identified from four fields in Wicomico County in Maryland, one field in Dorchester County in Maryland, and one field in Sussex County in Delaware, accounting for $24 \%$ of the total number of fields sampled. Race 2 was present in $75 \%$ of the fields in which one or two other races were isolated. Copresence of race 2 with race 0 , race 1 , or races 0 and 1 was observed in 1 (4\%), 4
(16\%), and $1(4 \%)$ of the fields, respectively.

All three races were present in the research field (Table 4). Among the 25 isolates obtained from the field, two (8\%), four $(16 \%)$, and $19(76 \%)$ isolates were identified as race 0 , race 1 , and race 2 , respectively.

Inoculum density of $F$. oxysporum f. sp. niveum. Fusarium oxysporum f. sp. niveum was detected in all commercial watermelon fields showing symptoms of Fusarium wilt when plant and soil samples were collected at harvest (Table 4). However, a significant range in inoculum densities was observed. The highest inoculum density of $F$. oxysporum f. sp. niveum $(5,109 \mathrm{CFU} / \mathrm{g}$ of soil) was found in Field 18 in Wicomico County, Maryland, whereas the lowest inoculum density (5 $\mathrm{CFU} / \mathrm{g}$ of soil) was found in Field 5 in Dorchester County. For most fields (73\%), including all fields surveyed in Delaware, the inoculum density of the pathogen fell between 100 and 1,200 CFU/g of soil. A large range was observed among the fields sampled in the ratio of pathogenic to total isolates of $F$. oxysporum obtained from dilution plating. This ratio ranged from 20 to $80 \%$, with a majority of the fields $(58 \%)$ sharing a ratio between 27 and $67 \%$ (data not shown). The ratio $(Y)$ was linearly increased with increasing inoculum density of $F$. oxysporum $\mathrm{f}$. sp. niveum $(X)$ in the

Table 2. Incidence (\%) of plants with Fusarium wilt for six differential watermelon cultivars inoculated with isolates of Fusarium oxysporum f. sp. niveum collected from a research field in Maryland in 1999 and 2000

\begin{tabular}{|c|c|c|c|c|c|c|c|c|}
\hline \multicolumn{2}{|c|}{ F. oxysporum f. sp. niveum } & \multicolumn{7}{|c|}{ Differential watermelon cultivar } \\
\hline Isolate ${ }^{w}$ & $\operatorname{Race}^{\mathrm{x}}$ & Calhoun Gray & Dixielee & Allsweet & Charleston Gray & Crimson Sweet & Sugar Baby & Mean \\
\hline F-17B-010 & 0 & $0^{\mathrm{y}}$ & 0 & 0 & 0 & 0 & 50 & 8 \\
\hline TX-471 & 0 & 0 & 0 & 0 & 7 & 5 & 78 & 15 \\
\hline ATCC-44293 & 1 & 13 & 14 & 29 & 31 & 48 & 76 & 35 \\
\hline F-17B-1-38 & 1 & 27 & 26 & 33 & 33 & 95 & 94 & 51 \\
\hline F-17B-R-5 & 1 & 33 & 25 & 47 & 61 & 52 & 100 & 53 \\
\hline TX-X1D & 2 & 63 & 59 & 67 & 86 & 81 & 100 & 76 \\
\hline F-17B-1-30 & 2 & 70 & 88 & 67 & 53 & 95 & 100 & 79 \\
\hline F-17B-1-20 & 2 & 60 & 77 & 73 & 69 & 100 & 100 & 80 \\
\hline F-17B-1-22 & 2 & 67 & 81 & 67 & 81 & 95 & 100 & 82 \\
\hline F-17B-R-1 & 2 & 60 & 59 & 93 & 85 & 100 & 100 & 83 \\
\hline F-17B-1-18 & 2 & 70 & 88 & 60 & 78 & 100 & 100 & 83 \\
\hline F-17B-1-10 & 2 & 67 & 78 & 67 & 85 & 100 & 100 & 83 \\
\hline F-17B-R-7 & 2 & 73 & 94 & 87 & 73 & 86 & 100 & 85 \\
\hline F-17B-1-25 & 2 & 67 & 71 & 87 & 100 & 100 & 100 & 88 \\
\hline F-17B-R-2 & 2 & 73 & 77 & 93 & 92 & 95 & 100 & 88 \\
\hline F-17B-1-29 & 2 & 83 & 67 & 100 & 100 & 100 & 100 & 92 \\
\hline $\operatorname{LSD}_{0.05^{\mathrm{z}}}$ & & 20 & 27 & 29 & 37 & 17 & 9 & \\
\hline Mean & & 55 & 60 & 65 & 69 & 83 & 97 & \\
\hline
\end{tabular}

${ }^{\text {w }}$ Thirteen isolates of Fusarium oxysporum f. sp. niveum were selected for presentation from 25 isolates obtained from a University of Maryland research field. The isolates represent the range of disease reactions caused by the three races of the pathogen inoculated onto the differential watermelon cultivars. Fifteen of the isolates were recovered from infected watermelon plants in 2000, and 10 isolates recovered from soil samples collected in the same field in 1999. TX-471 was the reference isolate for race 0 (obtained from B. D. Bruton of the USDA in Lane, OK), and ATCC-44293 and TX-X1D (ATCC62939) were the reference isolates for races 1 and 2, respectively (obtained from the American Type Culture Collection (ATCC) in Manassas, VA).

${ }^{x}$ Race designation was determined by inoculation of six differential watermelon cultivars $(12,15,22)$. Isolates were designated as: (i) race 0 if wilt incidence (>15\%) occurred only on Sugar Baby; (ii) race 1 if wilt incidence was $\leq 50 \%$ on Calhoun Gray, Dixielee, and Allsweet, with a mean wilt incidence over all six cultivars of 33 to $66 \%$; and (iii) race 2 if wilt incidence was $>50 \%$ on all six cultivars, with a mean wilt incidence of $>66 \%$.

y Percent wilt was calculated as the mean percentage of watermelon seedlings showing symptoms of Fusarium wilt for three replicate pots each containing

7 to 10 plants. Plants were rated for Fusarium wilt 3 to 4 weeks after inoculation ( $\sim 10^{5}$ conidia of $F$. oxysporum f. sp. niveum per $\mathrm{g}$ of potting medium). Plants were maintained in a greenhouse at 20 to $28^{\circ} \mathrm{C}$. Noninoculated control plants remained healthy.

${ }^{\mathrm{z}} \mathrm{LSD}_{0.05}$ is Fisher's protected least significant difference at $P \leq 0.05$ (31). Results of two repeated experiments were combined for analysis since interactions of experiment by isolate or cultivar were insignificant $(P \geq 0.07)$. Wilt values were arcsine-square root transformed to normalize data and then back-transformed after analysis for presentation. 
fields surveyed $\left(Y=0.00702 X+44.7 ; R^{2}=\right.$ 0.4; $P<0.0009$ ). In the research field (Field 26 ), inoculum density of the pathogen was high $(3,075 \mathrm{CFU} / \mathrm{g}$ of soil) in the soil samples collected at the end of the season in 2000 , and the ratio of pathogenic to total isolates of $F$. oxysporum was also high (80\%).

Disease potential, as measured by the incidence of Fusarium wilt on plants of the indicator cv. Sugar Baby planted into soil samples collected from each field, was high in 19 of the 25 commercial fields sampled (Fig. 1). Greater than 20\% incidence of wilt was observed on Sugar Baby for soil samples collected from these fields. Incidence of Fusarium wilt on Sugar Baby $(Y)$ increased significantly with an

Table 3. Mean incidence (\%) of plants with symptoms of Fusarium wilt for six differential watermelon cultivars inoculated with isolates of three races of Fusarium oxysporum f. sp. niveum collected from 25 commercial watermelon fields in Maryland and Delaware in 2000, and from a University of Maryland research field in Maryland in 1999 and 2000

\begin{tabular}{|c|c|c|c|c|c|c|c|c|c|}
\hline \multirow[b]{3}{*}{ Source of isolates } & \multirow{2}{*}{\multicolumn{2}{|c|}{ F. oxysporum f. sp. niveum }} & \multicolumn{7}{|c|}{ Differential watermelon cultivar ${ }^{w}$} \\
\hline & & & \multirow{2}{*}{$\begin{array}{c}\text { Calhoun } \\
\text { Gray }\end{array}$} & \multirow[b]{2}{*}{ Dixielee } & \multirow[b]{2}{*}{ Allsweet } & \multirow{2}{*}{$\begin{array}{c}\text { Charleston } \\
\text { Gray }\end{array}$} & \multirow{2}{*}{$\begin{array}{c}\text { Crimson } \\
\text { Sweet }\end{array}$} & \multirow{2}{*}{$\begin{array}{l}\text { Sugar } \\
\text { Baby }\end{array}$} & \multirow[b]{2}{*}{ Mean } \\
\hline & Race $^{x}$ & No. of isolates ${ }^{y}$ & & & & & & & \\
\hline \multirow[t]{3}{*}{ Commercial fields } & 0 & 13 & $0 \mathrm{a}^{\mathrm{z}}$ & $0 \mathrm{a}$ & $5 \mathrm{a}$ & $2 \mathrm{a}$ & $2 \mathrm{a}$ & $44 \mathrm{a}$ & 9 \\
\hline & 1 & 36 & $13 \mathrm{~b}$ & $22 \mathrm{~b}$ & $22 \mathrm{~b}$ & $51 \mathrm{~b}$ & $78 \mathrm{~b}$ & $99 \mathrm{~b}$ & 48 \\
\hline & 2 & 14 & $69 c$ & $64 \mathrm{c}$ & $66 \mathrm{c}$ & $80 \mathrm{c}$ & $90 \mathrm{c}$ & $100 \mathrm{~b}$ & 78 \\
\hline \multirow[t]{3}{*}{ Research field } & 0 & 2 & $0 \mathrm{a}$ & $0 \mathrm{a}$ & $7 \mathrm{a}$ & $4 \mathrm{a}$ & $2 a$ & $56 \mathrm{a}$ & 12 \\
\hline & 1 & 4 & $35 \mathrm{~b}$ & $39 \mathrm{~b}$ & $50 \mathrm{~b}$ & $61 \mathrm{~b}$ & $72 \mathrm{~b}$ & $99 \mathrm{~b}$ & 59 \\
\hline & 2 & 19 & $64 c$ & $70 \mathrm{c}$ & $74 \mathrm{c}$ & $77 \mathrm{~b}$ & $94 \mathrm{c}$ & $100 \mathrm{~b}$ & 80 \\
\hline
\end{tabular}

${ }^{w}$ Percent wilt was calculated as the mean percentage of watermelon seedlings showing symptoms of Fusarium wilt for three replicate pots each containing 7 to 10 plants. Plants were rated for Fusarium wilt 3 to 4 weeks after inoculation ( $10^{5}$ conidia of $F$. oxysporum f. sp. niveum per $\mathrm{g}$ of potting medium). Plants were maintained in a greenhouse at 20 to $28^{\circ} \mathrm{C}$. Noninoculated control plants remained healthy.

${ }^{x}$ Race designation was determined by inoculation of six differential watermelon cultivars $(12,15,22)$. Isolates were designated as: (i) race 0 if wilt incidence (>15\%) occurred only on Sugar Baby; (ii) race 1 if wilt incidence was $\leq 50 \%$ on Calhoun Gray, Dixielee, and Allsweet, with a mean wilt incidence over all six cultivars of 33 to $66 \%$; and (iii) race 2 if wilt incidence was $>50 \%$ on all six cultivars with a mean wilt incidence of $>66 \%$.

${ }^{\mathrm{y}}$ Isolates obtained from commercial fields were recovered from infected watermelon plants in 2000. Fifteen of the isolates obtained from the research plots were recovered from infected watermelon plants in 2000, and 10 isolates were recovered from soil samples collected from the same field in 1999.

${ }^{\mathrm{z}} \mathrm{LSD}_{0.05}$ is Fisher's protected least significant difference at $P \leq 0.05$ (31). Results of two experiments were combined for analysis since interactions of experiment by isolate or cultivar were insignificant $(P \geq 0.10)$. Wilt values were arcsine-square root transformed to normalize data and then backtransformed after analysis for presentation.

Table 4. Distribution of races and inoculum density of Fusarium oxysporum f. sp. niveum in 25 commercial watermelon crops (Fields 1 to 25 ) in Maryland (MD) and Delaware (DE) in 2000 and in one research crop (Field 26) in Maryland in 1999 and 2000

\begin{tabular}{|c|c|c|c|c|c|c|}
\hline \multirow[b]{2}{*}{ Field no. } & \multirow[b]{2}{*}{ Location (county, state) } & \multirow[b]{2}{*}{ Total no. of isolates ${ }^{y}$} & \multicolumn{3}{|c|}{$\operatorname{Race}^{x}$} & \multirow[b]{2}{*}{ Inoculum density (CFU/g of soil $)^{z}$} \\
\hline & & & $\mathbf{0}$ & 1 & 2 & \\
\hline 1 & Caroline, MD & 1 & 1 & $\ldots$ & $\ldots$ & 141 \\
\hline 2 & Caroline, MD & 1 & 1 & $\ldots$ & $\ldots$ & 1088 \\
\hline 3 & Caroline, MD & 2 & 1 & 1 & $\ldots$ & 714 \\
\hline 4 & Dorchester, MD & 2 & $\ldots$ & 2 & $\ldots$ & 383 \\
\hline 5 & Dorchester, MD & 2 & 2 & $\ldots$ & $\ldots$ & 5 \\
\hline 6 & Dorchester, MD & 1 & 1 & $\ldots$ & $\ldots$ & 57 \\
\hline 7 & Dorchester, MD & 7 & $\ldots$ & 3 & 4 & 1156 \\
\hline 8 & Wicomico, MD & 1 & 1 & $\ldots$ & $\ldots$ & 83 \\
\hline 9 & Wicomico, MD & 0 & $\ldots$ & $\ldots$ & $\ldots$ & 199 \\
\hline 10 & Wicomico, MD & 0 & $\ldots$ & $\ldots$ & $\ldots$ & 276 \\
\hline 11 & Wicomico, MD & 16 & $\ldots$ & 15 & 1 & 719 \\
\hline 12 & Wicomico, MD & 7 & 1 & 6 & $\ldots$ & 1844 \\
\hline 13 & Wicomico, MD & 2 & 1 & $\ldots$ & 1 & 202 \\
\hline 14 & Wicomico, MD & 0 & $\ldots$ & $\ldots$ & $\ldots$ & 1156 \\
\hline 15 & Wicomico, MD & 0 & $\ldots$ & $\ldots$ & $\ldots$ & 756 \\
\hline 16 & Wicomico, MD & 2 & $\ldots$ & 2 & $\ldots$ & 260 \\
\hline 17 & Wicomico, MD & 1 & 1 & $\ldots$ & $\ldots$ & 310 \\
\hline 18 & Wicomico, MD & 5 & $\ldots$ & 1 & 4 & 5109 \\
\hline 19 & Wicomico, MD & 4 & 1 & 2 & 1 & 1692 \\
\hline 20 & Sussex, DE & 0 & $\ldots$ & $\ldots$ & $\ldots$ & 570 \\
\hline 21 & Sussex, DE & 1 & 1 & $\ldots$ & $\ldots$ & 409 \\
\hline 22 & Sussex, DE & 6 & $\ldots$ & 3 & 3 & 107 \\
\hline 23 & Sussex, DE & 1 & 1 & $\ldots$ & $\ldots$ & 637 \\
\hline 24 & Sussex, DE & 1 & $\ldots$ & 1 & $\ldots$ & 127 \\
\hline 25 & Sussex, DE & 0 & $\ldots$ & $\ldots$ & $\ldots$ & 211 \\
\hline 26 & Wicomico, MD & 25 & 2 & 4 & 19 & 3075 \\
\hline Total & & 88 & 15 & 40 & 33 & \\
\hline
\end{tabular}

${ }^{x}$ The race of $F$. oxysporum f. sp. niveum for each isolate was determined based on disease reactions of six differentials watermelon cultivars inoculated with the isolate. Disease reaction was based on the mean wilt incidence in three replicate pots of 7 to 10 plants each for every isolate-cultivar combination. Plants were rated for Fusarium wilt 3 to 4 weeks after inoculation $\left(\sim 10^{5}\right.$ conidia of $F$. oxysporum $\mathrm{f}$. sp. niveum per g of potting medium). Plants were maintained in a greenhouse at 20 to $28^{\circ} \mathrm{C}$.

y Isolates obtained from commercial fields were recovered from infected watermelon plants in 2000 and used for race determination. Isolates obtained from the University of Maryland research field (Field 26) were recovered from infected watermelon plants in 2000 (15 isolates) and from soil samples in 1999 (10 isolates). Race determination was not conducted on $F$. oxysporum f. sp. niveum isolates collected from fields $9,10,14,15,20$, and 25 . Twelve to twenty plants showing symptoms of Fusarium wilt were sampled from each field.

${ }^{\mathrm{z}}$ Inoculum density in soil samples collected from each field during harvest in 2000 was estimated using soil dilution plating (three replicates per field, two dilutions per replicate, and two plates per dilution) and pathogenicity tests of random, representative colonies of $F$. oxysporum. 
increase in inoculum density $(X)$ in the soil $(P<0.0001)$. This relationship was characterized by the monomolecular equation, $Y$ $=1-\exp ^{[-a(X+b)]}$, in which $a=0.0013 \pm$ 0.0003 (standard error) proportion of plants showing symptoms of Fusarium wilt/CFU/ $\mathrm{g}$ of soil (the relative rate of increase in Fusarium wilt with an increase in inoculum density of $F$. oxysporum f. sp. niveum), and $b=166 \pm 106$ (standard error) CFU/g of soil (the minimum inoculum density of $F$. oxysporum f. sp. niveum required to induce wilt symptoms on Sugar Baby). Based on this equation, the estimated inoculum density required to cause $50 \%$ incidence of wilt on Sugar Baby $\left(\mathrm{ID}_{50}\right)$ was $367 \mathrm{CFU} / \mathrm{g}$ of soil.

\section{DISCUSSION}

Race 2 has been previously identified in Maryland and Delaware (33), but its distribution was unknown prior to this study. Race 2 was found in $24 \%$ of the commercial watermelon fields sampled, and present in three of the four counties surveyed in these two states. Race 2 was the predominant race isolated from the University of Maryland research field. The widespread occurrence of race 2 in this region is important in that the potential for further spread of race 2 increases the difficulty of managing Fusarium wilt of watermelon.

The source of introduction of race 2 of F. oxysporum $\mathrm{f}$. sp. niveum into Maryland and Delaware is unknown. Infected seeds or seedlings may spread isolates of this pathogen $(19,20,32)$. One of the commercial watermelon fields sampled in the study (Field 7) may have become contaminated with isolates of race 2 on transplant seedlings. This field had no previous history of Fusarium wilt, but the watermelon transplants imported from Florida had severe symptoms of Fusarium wilt in 2000 (Everts and Zhou, communications with the farmer). Four of seven isolates of $F$. oxysporum f. sp. niveum from this field were race 2 , and this was the only field in Dorchester County, MD where race 2 was detected. Race 2 is well established in Florida $(15,22)$.

The presence of multiple races of $F$. oxysporum $\mathrm{f}$. $\mathrm{sp}$. niveum within the same field is documented in this study. Almost one-third of the commercial fields surveyed were infested with two or all three races. For three-fourths of these fields, races 0,1 , or both were copresent with race 2. Presence of race 2 has the potential to alter the existing race composition in an infested field. The population level of race 2 could be selectively increased after subsequent plantings of resistant watermelon cultivars (to races 0 and 1) (12). The predominance of race 2 isolates from our research field suggests that race 2 was selectively increased by repeated plantings of resistant cultivars.

The common occurrence of race 0 in commercial watermelon fields in Maryland and Delaware was unexpected. Race 0 occurred in almost one-half of the commercial fields surveyed (12 of 25 fields) across all four counties. This observation is in contrast with previous studies that report limited occurrences of race $0(15,22)$.

The ability to separate races 2 and 1 using the differential cultivars increased with an increase in resistance of the cultivars to F. oxysporum f. sp. niveum. The greatest distinction between isolates of race 2 and race 1 was observed on the watermelon $\mathrm{cv}$. Calhoun Gray, followed by Dixielee and Allsweet. Charleston Gray and Crimson Sweet were not effective for differentiating race 2 from race 1 because the incidence of wilt caused by some isolates overlapped on both cultivars. These results support the results of Larkin et al. (15) that Calhoun Gray and Dixielee effectively differentiated race 2 from race 1 , while Charleston Gray and Crimson Sweet did not.

A clear distinction between race 1 and race 0 was observed in this study in that race 0 isolates caused wilt on Sugar Baby but were unable to cause significant wilt on the other five differential cultivars. Similar results were observed when Martyn (19) tested a single isolate of race 0 and two isolates of race 1 . However, others $(1,15)$ have reported little difference in virulence of race 0 from race 1 on differential hosts.

Vegetative compatibility grouping (VCG) is another useful tool to aid the separation of isolates of $F$. oxysporum $\mathrm{f}$. sp. niveum into races and to characterize the diversity and possible origin of local populations of this pathogen $(9,12,15)$. VCG characterization of Maryland and Delaware isolates of $F$. oxysporum $\mathrm{f}$. sp. niveum is under investigation.

The inoculum densities of $F$. oxysporum f. sp. niveum in commercial fields in Maryland and Delaware in which symptoms of Fusarium wilt were observed ranged from 100 to $1,200 \mathrm{CFU} / \mathrm{g}$ of soil. Netzer (28) reported a similar range (400 to 1,400 $\mathrm{CFU} / \mathrm{g}$ of soil) in a heavily infected field of Sugar Baby in Israel. Martyn et al. (21) used an inoculum level of $750 \mathrm{CFU} / \mathrm{g}$ of soil to infest microplots to simulate field conditions for a study on induced resistance in watermelon to Fusarium wilt. In our research field, the pathogen population was extremely high compared to the commercial fields surveyed, with an exception of Field 18 (5,109 CFU/g of soil) in which a severe outbreak of Fusarium wilt was observed. The high population in the research field is probably due to the longterm monoculture of watermelon.

The ratio of pathogenic to total population of $F$. oxysporum in fields surveyed in this study was positively correlated with inoculum density of $F$. oxysporum f. sp. niveum. The accompanying increase of the ratio of pathogenic population with increasing inoculum density is apparently due to residue of infected watermelon plants in the fields. Host plant has been considered the primary source of increasing of Fusarium wilt pathogen populations

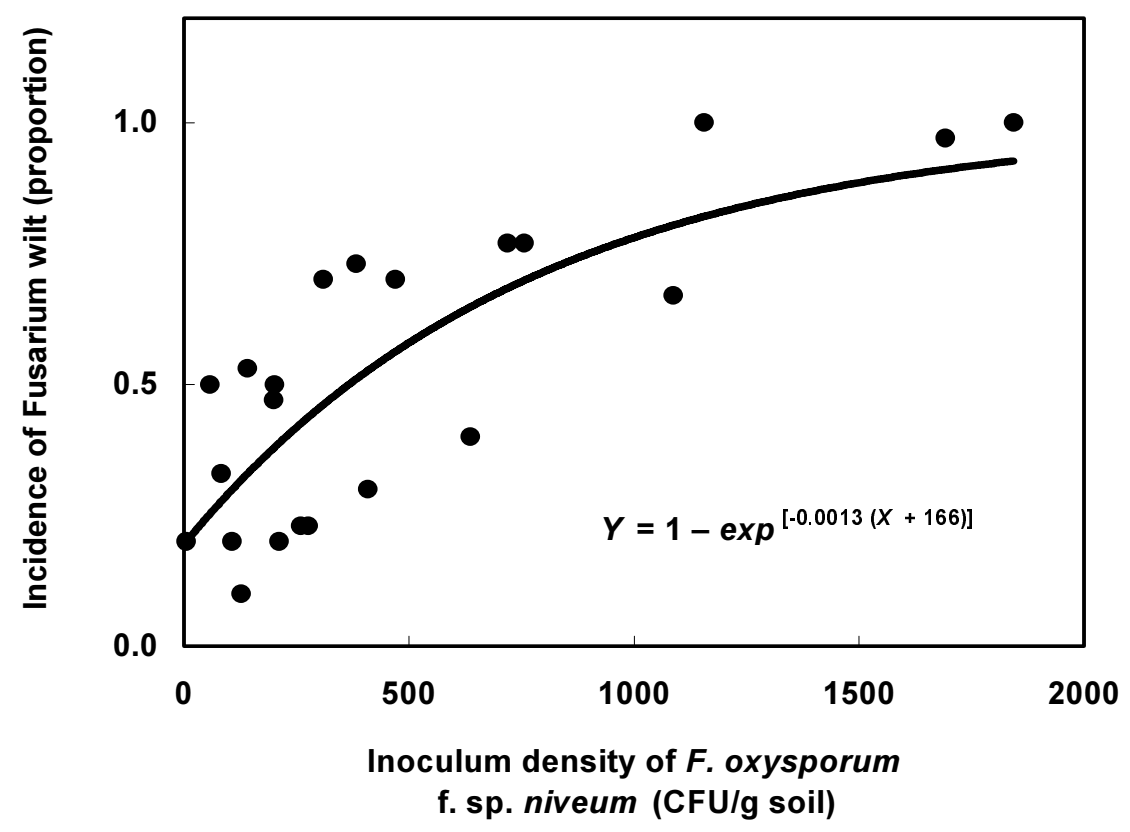

Fig. 1. Disease potential $(Y)$ in relation to inoculum density $(X)$ of Fusarium oxysporum $\mathrm{f}$. sp. niveum in soil samples collected from 25 commercial watermelon fields in Maryland and Delaware. Disease potential was measured as the proportion of seedlings developing Fusarium wilt for the susceptible watermelon cv. Sugar Baby planted in soil samples collected from each field. Each circle represents the mean of three replicate pots of 10 plants each. Inoculum density in the soil samples was estimated using soil dilution plating and pathogenicity tests of random, representative colonies of $F$. oxysporum. The predicted curve was estimated using nonlinear regression (27) as a monomolecular equation. 
(24). The ratios of pathogenic population in our commercial fields surveyed were generally higher than those reported in watermelon research plots in Florida where the majority of the ratios were between 10 and $40 \%(12,16)$.

The inoculum density in the fields sampled may have been overestimated because soilborne fungi are not uniformly distributed in infested fields (28). The soil samples collected in this study were taken from around the base of plants showing symptoms of Fusarium wilt, where high densities of the fungus can be expected compared to soil sampled further from the plants. Some reports $(11,25)$ have indicated that levels of $F$. oxysporum in field soils may not correlate with incidence of Fusarium wilt. Incidence of Fusarium wilt of watermelon in our study was significantly correlated with inoculum density of $F$. oxysporum f. sp. niveum, regardless of race structure of populations of the fungus in the fields. This relationship was characterized by an equation that estimated two inoculum density-related parameters: the relative rate of disease increase with increasing inoculum density of $F$. oxysporum f. sp. niveum, and the estimated inoculum density required to cause wilt in $50 \%$ of the plants of the susceptible cv. Sugar Baby $\left(\mathrm{ID}_{50}\right)$. This information, together with an understanding of the range of inoculum densities of $F$. oxysporum $\mathrm{f}$. sp. niveum in the commercial fields, will help contribute to the development of effective Fusarium wilt management strategies and help determine concentrations of inoculum of this pathogen needed to infest soils for research purposes in greenhouse or field trials.

Presence of the highly aggressive race 2 as well as high inoculum densities of $F$. oxysporum $\mathrm{f}$. sp. niveum in the commercial fields suggests that Fusarium wilt remains a threat to watermelon production in Maryland and Delaware. Employing multiple tactics, rather than cultivar resistance alone, appears to be most appropriate for management of Fusarium wilt of watermelon in the region.

\section{ACKNOWLEDGMENTS}

We thank B. D. Bruton for supplying isolates of F. oxysporum f. sp. niveum and providing valuable suggestions on inoculation methods; anonymous referees for critical review that greatly improved the text; C. E. Beste for helpful comments on the manuscript; D. K. Armentrout for technical assis- tance; E. Johnson and B. Gallagher for assistance with field surveys; and Hollar Seeds Company for providing seeds.

\section{LITERATURE CITED}

1. Armstrong, G. M., and Armstrong, J. K. 1978. Formae speciales and races of Fusarium oxysporum causing wilts of the Cucurbitaceae. Phytopathology 68:19-28.

2. Barness, G. L. 1972. Differential pathogenicity of Fusarium oxysporum f. sp. niveum to certain wilt-resistant watermelon cultivars. Plant Dis. Rep. 56:1022-1026.

3. Bruton, B. D., and Damicone, J. P. 1999. Fusarium wilt of watermelon: Impact of race 2 of Fusarium oxysporum f. sp. niveum on watermelon production in Texas and Oklahoma. Subtrop. Plant Sci. 51:4-9.

4. Bruton, B. D., Patterson, C. L., and Martyn, R. D. 1988. Fusarium wilt ( $F$. oxysporum $\mathrm{f}$. sp. niveum race 2) of watermelon in Oklahoma. Plant Dis. 72:734.

5. Cirulli, M. 1972. Variation of pathogenicity in Fusarium oxysporum f. sp. niveum and resistance in watermelon cultivars. Pages 491-500 in: Actas III Congr. Union Fitopathol. Mediterr. Oeiras, Portugal.

6. Crall, J. M. 1963. Physiologic specialization in Fusarium oxysporum f. sp. niveum. (Abstr.) Phytopathology 53:873.

7. Elmstrom, G. W., and Hopkins, D. L. 1981. Resistance of watermelon cultivars to Fusarium wilt. Plant Dis. 65:825-827.

8. Gonzalez-Torres, R., Melero-Vara, J., GomezVazquez, J., and Jimenez Diaz, R. M. 1993. The effects of soil solarization and soil fumigation on Fusarium wilt of watermelon grown in plastic houses in south-eastern Spain. Plant Pathol. 42:858-864.

9. Gordon, T. R., and Martyn, R. D. 1997. The evolutionary biology of Fusarium oxysporum. Annu. Rev. Phytopathol. 35:111-128.

10. Hopkins, D. L., and Elmstrom, G. W. 1974. Chemical control of watermelon damping-off and seedling wilt. Plant Dis. Rep. 58:114-117.

11. Hopkins, D. L., and Elmstrom, G. W. 1984. Fusarium wilt in watermelon cultivars grown in a 4-year monoculture. Plant Dis. 68:129-131.

12. Hopkins, D. L., Lobinske, R. J., and Larkin, R. P. 1992. Selection for Fusarium oxysporum f. sp. niveum race 2 in monocultures of watermelon cultivars resistant to Fusarium wilt. Phytopathology 82:290-293.

13. Ioannou, N., and Poullis, C. A. 1991. Fusarium wilt of resistant watermelon cultivars associated with a highly virulent local strain of Fusarium oxysporum f. sp. niveum. Tech. Bull. 129, Agric. Res. Inst. Nicosia, Cyprus.

14. Komada, H. 1975. Development of a selective medium for quantitative isolation of Fusarium oxysporum from natural soil. Rev. Plant Prot. Res. 8:114-124.

15. Larkin, R. P., Hopkins, D. L., and Martin, F. N. 1990. Vegetative compatibility within Fusarium oxysporum f. sp. niveum and its relationship to virulence, aggressiveness, and race. Can. J. Microbiol. 36:352-358.

16. Larkin, R. P., Hopkins, D. L., and Martin, F. N. 1993. Ecology of Fusarium oxysporum $\mathrm{f}$. sp. niveum in soils suppressive and conductive to Fusarium wilt of watermelon. Phytopathology 83:1105-1116.

17. Latin, R. X., and Snell, S. J. 1986. Comparison of methods for inoculation of muskmelon with Fusarium oxysporum f. sp. melonis. Plant Dis. 70:297-300.

18. Martyn, R. D. 1985. An aggressive race of Fusarium oxysporum $\mathrm{f}$. sp. niveum new to the United States. Plant Dis. 69:1007.

19. Martyn, R. D. 1987. Fusarium oxysporum f. sp. niveum race 2: A highly aggressive race new to the United States. Plant Dis. 71:233-236.

20. Martyn, R. D. 1996. Fusarium wilt of watermelon. Pages 13-14 in: Compendium of $\mathrm{Cu}$ curbit Diseases. T. A. Zitter, D. L. Hopkins, and C. E. Thomas eds. The American Phytopathological Society, St. Paul, MN.

21. Martyn, R. D., Biles, C. L., and Dillard, E. A., III. 1991. Induced resistance to Fusarium wilt of watermelon under simulated field conditions. Plant Dis. 75:874-877.

22. Martyn, R. D., and Bruton, B. D. 1989. An initial survey of the United States for races of Fusarium oxysporum f. sp. niveum. HortScience 24:696-698.

23. Martyn, R. D., and Hartz, T. K. 1986. Use of soil solarization to control Fusarium wilt of watermelon. Plant Dis. 70:762-766.

24. Martyn, R. D., and McLaughlin, R. J. 1983. Effects of inoculum concentration on the apparent resistance of watermelons to Fusarium oxysporum f. sp. niveum. Plant Dis. 67:493-495.

25. Nash, S. M., and Snyder, W. C. 1962. Quantitative estimation by plate counts of propagules of the bean root rot Fusarium in field soils. Phytopathology 52:567-572.

26. Nelson, P. E., Toussoun, T. A., and Marasas, W. F. O. 1983. Fusarium Species: An Illustrated Manual for Identification. Pennsylvania State University Press, University Park, PA.

27. Neter, J., Kutner, M. H., Nachtsheim, C. J., and Wasserman, W. 1996. Applied Linear Regression Models. Times Mirror Higher Education Group, Inc., Chicago.

28. Netzer, D. 1976. Physiological races and soil population level of Fusarium wilt of watermelon. Phytoparasitica 4:131-136.

29. Netzer, D., and Dishon, I. 1973. Screening for resistance and physiological specialization of Fusarium oxysporum in watermelon and muskmelon. (Abstr. 941) Second Int. Congr. Plant Pathol. Minneapolis, MN.

30. Netzer, D., and Weintall, C. 1980. Inheritance of resistance in watermelon to race 1 of Fusarium oxysporum f. sp. niveum. Plant Dis. 64:853-854.

31. Steel, R. G. D., Torrie, J. H., and Dickey, D. A. 1997. Principles and Procedures of Statistics: A Biometrical Approach. McGraw-Hill, Inc., New York.

32. Taubenhaus, J. J. 1935. Seeds of watermelon and okra as possible carriers of Fusarium wilt (Abstr.) Phytopathology 25:969.

33. Zhou, X. G., and Everts, K. L. 2001. First report of the occurrence of Fusarium oxysporum $\mathrm{f}$. sp. niveum race 2 in commercial watermelon production areas of Maryland and Delaware. Plant Dis. 85:1291. 